\begin{tabular}{|l|c|c|c|c|}
\hline $\begin{array}{l}\text { Cuadernos de Investigación Geográfica } \\
\text { Geographical Research Letters }\end{array}$ & 2019 & N $^{\circ} 45(2)$ & pp. 551-569 & eISSN 1697-9540 \\
\hline
\end{tabular}

\title{
MODELLING ABOVEGROUND NET PRIMARY PRODUCTION (ANPP) OF AN ATLANTIC MOUNTAIN GRASSLAND BASED ON TIME SERIES APPROACH
}

\author{
A. SALABERRIA, G. GARCÍA-BAQUERO, I. ODRIOZOLA, A. ALDEZABAL* \\ Department of Plant Biology and Ecology, Faculty of Science and Technology, \\ University of the Basque Country, UPV/EHU, 48940 Leioa, Basque Country, Spain.
}

\begin{abstract}
Because primary productivity is related both with the energy that sustains food webs and with species diversity, it is usually considered a key ecosystem property and a reliable indicator of available forage. In this work the aboveground net primary production (ANPP) of an Atlantic mountain grassland system was modelled in order to attempt producing short-term forecasts. Since grazing influences productivity, two treatment levels (grazing and exclusion) were experimentally applied in each of three field sites. Monthly ANPP data were then collected over three consecutive vegetative periods (2006-2008), thereby obtaining six time series (one per plot). Since no significant differences among sites (within treatments) were found, these six series were later reduced through averaging to only two series (one per treatment level). Two kinds of statistical models were then used to attempt monthly ANPP forecasting: exponential smoothing methods and ARIMA models. Both methodologies turned out to produce inadequate forecasts due to the presence of marked local features (innovative outliers) in our relatively short time-series data. Nonetheless, useful information for a more innovative shepherding management was revealed (e.g. the presence of within-year variation in ANPP, and differences between the grazing and exclusion treatments). Longer data series, which would require a more demanding effort in sampling investment, are likely necessary in order to obtain adequate forecasts using these time series methodologies.
\end{abstract}

Modelado de la producción primaria neta aérea (ANPP) de un pastizal atlántico de montaña basado en el análisis de series temporales

RESUMEN: Debido a que la producción primaria está relacionada tanto con la energía que sustenta las redes tróficas como con la diversidad de especies, generalmente se considera una propiedad clave del ecosistema y un indicador fiable del forraje disponible. En este trabajo se modeló la producción primaria neta aérea (ANPP) de un sistema de pastizales atlánticos de montaña con el fin de intentar pronosticarla a corto plazo. Como el pastoreo influye en la productividad, se aplicaron experimentalmente dos niveles de tratamiento (pastoreo 
y exclusión) en cada uno de los tres sitios de estudio. Los datos mensuales de ANPP se recolectaron a lo largo de tres períodos vegetativos consecutivos (2006-2008), obteniendo así seis series temporales (una por parcela). Dado que no se encontraron diferencias significativas entre los sitios (dentro de los tratamientos), estas seis series fueron promediadas y reducidas a dos (una por nivel de tratamiento). Posteriormente, se utilizaron dos tipos de modelos estadísticos para pronosticar la ANPP mensual: métodos de suavizado exponencial y modelos ARIMA. Ambas metodologías arrojaron pronósticos inadecuados debido a la presencia de características locales marcadas (valores atípicos innovadores) en nuestros datos de series temporales relativamente cortas. No obstante, se reveló información útil para un diseño de manejo del pastoreo más adecuado (por ejemplo, la presencia de variación dentro de un año en la ANPP $y$ diferencias entre los tratamientos de pastoreo y exclusión). Es probable que se necesiten series de datos más largas, lo que requeriría un esfuerzo más exigente en la inversión de muestreo, para obtener predicciones adecuadas utilizando estas metodologías de series temporales.

Keywords: ARIMA models, net primary production, forecasting, Holt-Winters methods, livestock exclusion, manipulative experiment, Atlantic mountains.

Palabras clave: modelos ARIMA, producción primaria neta, predicción, métodos Holt-Winters, exclusión del ganado, experimento manipulativo, Montañas atlánticas.

Received: 21 February 2018

Accepted: 15 July 2018

*Corresponding author: Arantza Aldezabal, Department of Plant Biology and Ecology, Faculty of Science and Technology, University of the Basque Country, UPV/EHU, 48940 Leioa, Basque Country, Spain. E-mail address: arantza.aldezabal@ehu.eus.

\section{Introduction}

Plant productivity is, in essence, the dry matter produced by plants during a given time (Singh et al., 1975), where the underlying process is the fixation of atmospheric inorganic carbon into organic compounds by the photosynthesis. More specifically, aboveground net primary production (ANPP) is the fraction of gross productivity effectively fixed by aboveground plant organs once loses due to plant respiration have been taken into account.

ANPP is a key property of ecosystems because it is related with the energy that sustains the whole food web (McNaughton, 1985; McNaughton et al., 1989). Furthermore, some studies have suggested that the more energy available in the autotrophic level, the higher species diversity there is (De Angelis, 1980; Wright, 1983; Duffy et al., 2017), although this is a controversial topic and many others have asserted that there is no bivariate correlation between productivity and diversity 
(Adler et al., 2011; Fox, 2013) or that this relationship strongly depends on the type of community (Mittelbach et al., 2001). In addition to being useful for community characterisation, ANPP is a reliable indicator of available forage and modulates the effect of grazing on several ecosystem functions (Díaz et al., 2007; Peco et al., 2017). For this reason, some studies have measured livestock carrying capacity based on productivity (Golluscio et al., 2015; Zhang et al., 2016), thereby providing a useful tool for management.

Productivity depends mainly on chemical soil properties (Fay et al., 2015; LeBauer and Treseder, 2008) and climate variables (Chapin III et al., 2011). Although annual precipitation is revealed as good predictor of broad-scale ANPP (La Pierre et al., 2016), at a local scale productivity is better explained through precipitation patterns and nutrient availability (La Pierre et al., 2016). Moreover, climate patterns which take into account growth cycles and phenology help explaining ANPP (La Pierre et al., 2011). Since ANPP influencing factors vary within years, ANPP is also thought to vary seasonally, except in tropical areas where seasonality may not be marked.

Some of the well-known consequences of the abandonment of livestock in grasslands include biomass accumulation (Patton et al., 2007), reduction of forage quality (Semmartin et al., 2004) and encroachment by woody plant species (LasantaMartínez et al., 2005; Gartzia et al., 2014). However, livestock grazing may affect grassland functions and ANPP via more subtle mechanisms. Grazing itself comprises not only the cutting and consumption of organic matter by grazers, but also trampling and fertilization by faeces deposition. For instance, low to moderate grazing intensity may enhance ANPP through grassland fertilization by animal urine and faeces (Frank and McNaughton, 1993; McNaughton et al., 1997), but it also may reduce ANPP via ecological mechanisms (non-specific disturbance) that allow the co-existence of highly productive species with less productive ones (Altesor et al., 2005; Tang et al., 2017). Moreover, the topsoil thermal regime and moisture conditions vary due to grazers activity (Gass and Binkley, 2011; Schrama et al., 2013), or because of livestock exclusion (Aalto et al., 2013; Odriozola et al., 2014). Therefore, ANPP fluctuates depending on the stocking density.

Despite the strong evidence suggesting variations in available forage due to changes in primary productivity (Fabricante et al., 2009), few studies have investigated withinyear productivity fluctuations. This is likely due to methodological limitations leading to lack of appropriate data, because primary productivity is ordinarily estimated as annual productivity rather than as monthly productivity (La Pierre et al., 2011, 2016). To the best of our knowledge, previous attempts to model ANPP have not tackled this within-year variation by means of time-series modelling and, for this reason, they may have missed essential features in data structure useful for the prediction of plant biomass growth.

To explore this issue, we conducted an experiment in the Aralar Natural Park, using monthly (not annual) time series data of ANPP, together with an appropriate set of statistical techniques such as time series data decomposition and forecasting. We aimed 
to measure and model change in primary productivity of Aralar grasslands under either grazing or grazing exclusion conditions, and to attempt the production of short-term forecasts.

\section{Material and methods}

\subsection{Study area}

The Atlantic grasslands of the Basque mountains provide important food resources to livestock, managed in short transhumance, from May (or June) to October (or November). Our experiment was developed in the semi-natural temperate grassland system of the Aralar Natural Park (11,000 ha), Basque Country, Northern Iberian Peninsula. The bedrock in the Aralar range is mainly calcareous (Gibbons and Moreno, 2002). The climate is oceanic temperate, with average (2006-2008) annual precipitation equal to $1331 \mathrm{~L} \mathrm{~m}^{-2}$ and mean monthly temperature in the same interval equal to $7.0^{\circ} \mathrm{C}$. Due to this rainfall regime, the upper layers in the Aralar soils have become moderately acidic. Traditionally, the Aralar area has been used for livestock grazing and this activity has shaped the landscape, creating and maintaining large prairies. As a consequence, graminoid species diversity is high, with Festuca nigrescens Lam. and Agrostis capillaris L. being the dominant species (Odriozola et al., 2017). These grasslands are phytosociologically called Jasiono laevis-Danthonietum decumbentis (Loidi, 1983) and are considered a priority habitat (6230 subtype a) by the Habitat Directive (EC, 2013). Altogether, the habitat occupies more than 1980 ha within the Special Area of Conservation Aralar (BOPV, 2016).

\subsection{Experimental description}

The experiment used two paired plots in three different field sites: "Uzkuiti" $\left(43^{\circ} 0\right.$ '

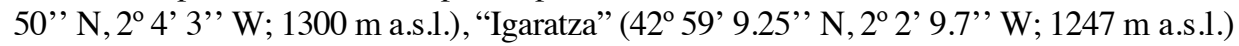

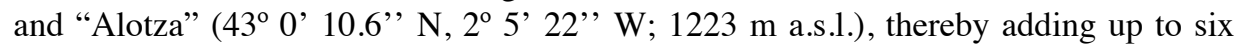
experimental plots. In order to simulate grazing abandonment, one plot $(50 \times 50 \mathrm{~m})$ in each site was fenced (May 2005) whereas another plot of the same size was delimited next to it. Therefore, two experimental (manipulative) treatment levels were used in each site: livestock exclusion in the enclosed plots (Fenced level) (Fig. 1) and free grazing in the simply delimited plots (Grazed level). In the latter, the grazing regime was not altered and large herbivores (dairy sheep, cattle and horses) were able to graze freely during the vegetative season just in the same stocking rates of the park (3.2 Livestock Unit ha-1 day $^{-1}$ ) (Odriozola et al., 2014).

In our experiment, monthly aboveground net primary production (ANPP) was defined as the weight (dry matter) of live biomass grown during one month (Singh et al., 1975). Monthly ANPP was measured in both fenced and grazed plots between January 2006 and December 2008, harvesting three to four $1 \mathrm{~m}^{2}$-quadrats per plot. Successive aboveground cuttings of standing crop of biomass were carried out at intervals of 25-30 days during the vegetative period (from the beginning of May, just after the snowmelt, to late October, before winter), so six monthly ANPP were 
measured per year and plot during the growing season. Since the average temperature in the non-vegetative season (between November and April) was consistently lower than $5^{\circ} \mathrm{C}$, the productivities of those months were insignificant and hence assumed to be zero. Thereby 36-month productivity values were recorded in each of the three fenced plots and an equal number were recorded for the grazed plots. Therefore, the whole production cycle was covered.

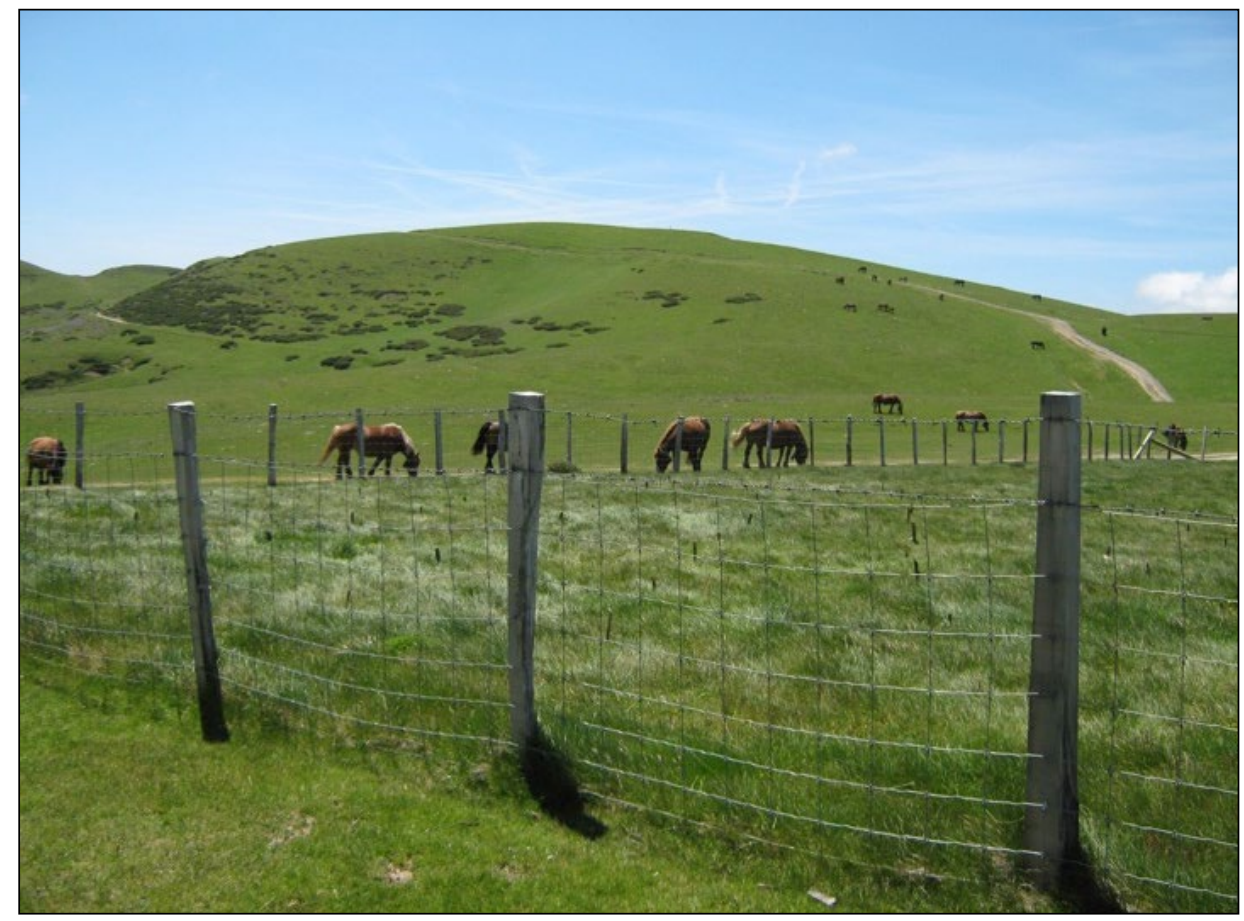

Figure 1. General view of the enclosed plot (Fenced level) of Igaratza in July 2008, with horses and mares grazing around the fence (Grazed level).

Plant standing biomass was clipped at the ground level to ensure a uniform clipping height, and the percentage of live biomass was estimated visually. Samples were later dried at $65^{\circ} \mathrm{C}$ for as much time as required (at least $48 \mathrm{~h}$ ), so as to avoid moisture-dependent weight fluctuations. Finally, mean live biomass (grams of dry matter per square metre) was obtained per plot before calculating monthly ANPP.

Since there are different methods to calculate ANPP, we chose the positive increment of live biomass recommended by Singh et al. (1975). The procedure of ANPP estimation was slightly different depending on the treatment. In the fenced plots, mean live biomass (LB) was calculated by harvesting randomly chosen 3-4 quadrats $(1 \times 1 \mathrm{~m})$. The ANPP of a known month could be measured by subtracting the mean live biomass $\left(\mathrm{LB}_{\text {fence }}\right)$ of the previous month $\left(\mathrm{t}_{\mathrm{n}}\right)$ from the live biomass of the current month $\left(\mathrm{t}_{\mathrm{n}+1}\right)$. In the grazed plots, $3-4$ temporary cages $(1.5 \times 1.5 \mathrm{~m})$ were used 
to avoid livestock eating herbage for one month (Frank et al., 2002). Standing live biomass was then clipped simultaneously inside the cages $\left(\mathrm{LB}_{\text {cage }}\right)$ and in the grazed plots $\left(\mathrm{LB}_{\text {grazed }}\right)$. Cages were then randomly moved to other points within the grazed plot allowing the growth of biomass during the next month $\left(t_{n+1}\right)$. In the case of grazed treatment, ANPP was measured by subtracting the previous month live biomass on the grazed plot ( $\mathrm{LB}_{\text {grazed }}$ in $t_{\mathrm{n}}$ ) from the current live biomass inside the cages ( $\mathrm{LB}_{\text {cage }}$ in $\mathrm{t}_{\mathrm{n}+1}$ ). That is:

$$
\begin{aligned}
& \text { Monthly ANPP from } t_{n} \text { to }{ }_{t n+1} \text { in fenced treatment: Mean } \mathrm{LB}_{\text {fence, } n+1}-\text { Mean } \mathrm{LB}_{\text {fence, } \mathrm{n}}
\end{aligned}
$$

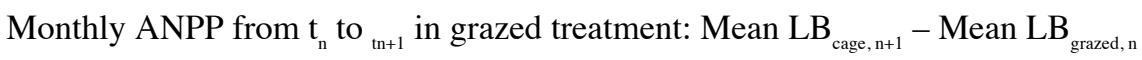

\subsection{Data analysis}

In order to model monthly ANPP between January 2006 and December 2008, several statistical techniques for time series analysis were conducted using R software ( $R$ core team, 2015). Since ANOVA analysis of this very same dataset provided no evidence of between-site differences (see Supplementary Material, Appendix 1), average monthly ANPP series according to treatment were computed. Hence, the original six data series were reduced to just two: one (average) time series for the fenced plots and another one for the grazed plots, each of them composed of 36 (average) values.

In the first of our analyses the characterisation of both time series was achieved through decomposition into three components: trend, regular component (seasonality) and irregular component (noise). Both additive and multiplicative decompositions (Cryer and Chan, 2008) were attempted by means of the function decompose() (package "stats" of base R), because the goal of this analysis was to explore which type of model better fitted the available data, which exhibit a marked feature: an unexpected increase in productivity for 2008 .

Productivity for the following years could then be forecasted through either explicative regression models (using variables such as temperature or precipitation as predictors) or non-explicative models. Since the aim of this study was to predict future values based on past values, two non-explicative analyses were conducted. After careful consideration of the potentially useful available models and the fact that a priori we ignored which could be the best, we attempted modelling using both the so-called exponential smoothing method and seasonal ARIMA (autoregressive integrated moving average) models. Therefore, in the second set of analyses, one exponential smoothing method was used (Coghlan, 2014) in order to produce shortterm ANPP forecasting. As decomposition revealed both linear trend and seasonal components, a model of type A-A (Hyndman and Khandakar, 2008) was found to be appropriate. However, the increase of seasonality in 2008 suggested that the data could better fit a multiplicative seasonal A-M model (Hyndman and Khandakar, 2008). Consequently, exponential smoothing methods of A-A and A-M series were applied. Function HoltWinters() (package "stats" of base R) was used to produce one-step ahead forecasts called traditionally Holt Winters methods (Winters, 1960; Holt, 2004). 
In the third analysis, a model-building strategy (Cryer and Chan, 2008) was developed in order to produce seasonal ARIMA model forecasts (Hyndman and Athanasopoulos, 2012) for each treatment level. First of all, model assumptions were checked (Cryer and Chan, 2008) by means of time series plots, autocorrelation plots (ACF) and partial autocorrelation plots (PACF), created through the function tsdisplay() of the package "forecast" (Hyndman, 2017). A logarithmic transformation was applied to meet the criterion of additivity and seasonal differencing was subsequently applied to achieve stationarity. Once both series were suitable for applying ARIMA models, a tentative model was chosen through the function auto.arima() of the same package. In the next step, function arimax() of the package "TSA" (Chan and Ripley, 2012), which uses maximum likelihood, confirmed the need to keep in the fitted models all the parameters suggested by autoarima(). Outlier values were then modelled to improve overall performance, using detectIO() and detectAO() of "TSA" (Box et al., 2008). Finally, when the models were validated (i.e. after checking for normality, null mean and independence contrasts of the residual values), future values were forecasted using forecast.Arima() of "forecast".

The $\mathrm{R}$ code including the original dataset and the three analyses are given in the Supplementary Material, Appendix S1.

\section{Results}

In general terms, exploratory analysis revealed consistently higher ANPP in the fenced plots than in the grazed ones $\left(F_{1,4}=20.2 ; p\right.$-value $\left.=0.011\right)$ (Fig. S1 in Appendix 2, Supplementary Material); likewise, differences among years were also significant $\left(F_{2.4}=10.3 ; p\right.$-value $\left.=0.027\right)$. By contrast, there was no significant difference in ANPP among sites $\left(F_{2,4}=1.7 ; p\right.$-value $\left.=0.288\right)$. Average (across sites) annual ANPP $\left(\mathrm{g} \mathrm{m}^{-2}\right)$ under grazing exclusion conditions was found to be 266.0 (in the year 2006), 300.8 (in 2007), and 549.5 (in 2008). Average (across sites) annual ANPP $\left(\mathrm{g} \mathrm{m}^{-2}\right)$ under grazing conditions was found to be 125.3 (in the year 2006), 206.9 (in 2007), and 259.6 (in 2008). Productivity in 2008 was, in general terms, particularly large.

\subsection{Characterisation by time series decomposition}

Decomposition revealed an increasing slope, a feature that is essentially due to the high productivity observed in 2008 (Fig. 2, trend component). The seasonal coefficients revealed a big peak of productivity in May and a second smaller peak in August in both series (Fig. 2, seasonal component). A third peak at the end of summer appeared, but only in the fenced series (Fig. 2, seasonal component). Thereby, the monthly ANPP series multiplicative decomposition showed the presence of changes in productivity, both within years (seasonality) and between years (positive linear trend) (Fig. 2). The results were similar when the additive decomposition model was tried (Fig. S2 in Appendix 2, Supplementary Material). 


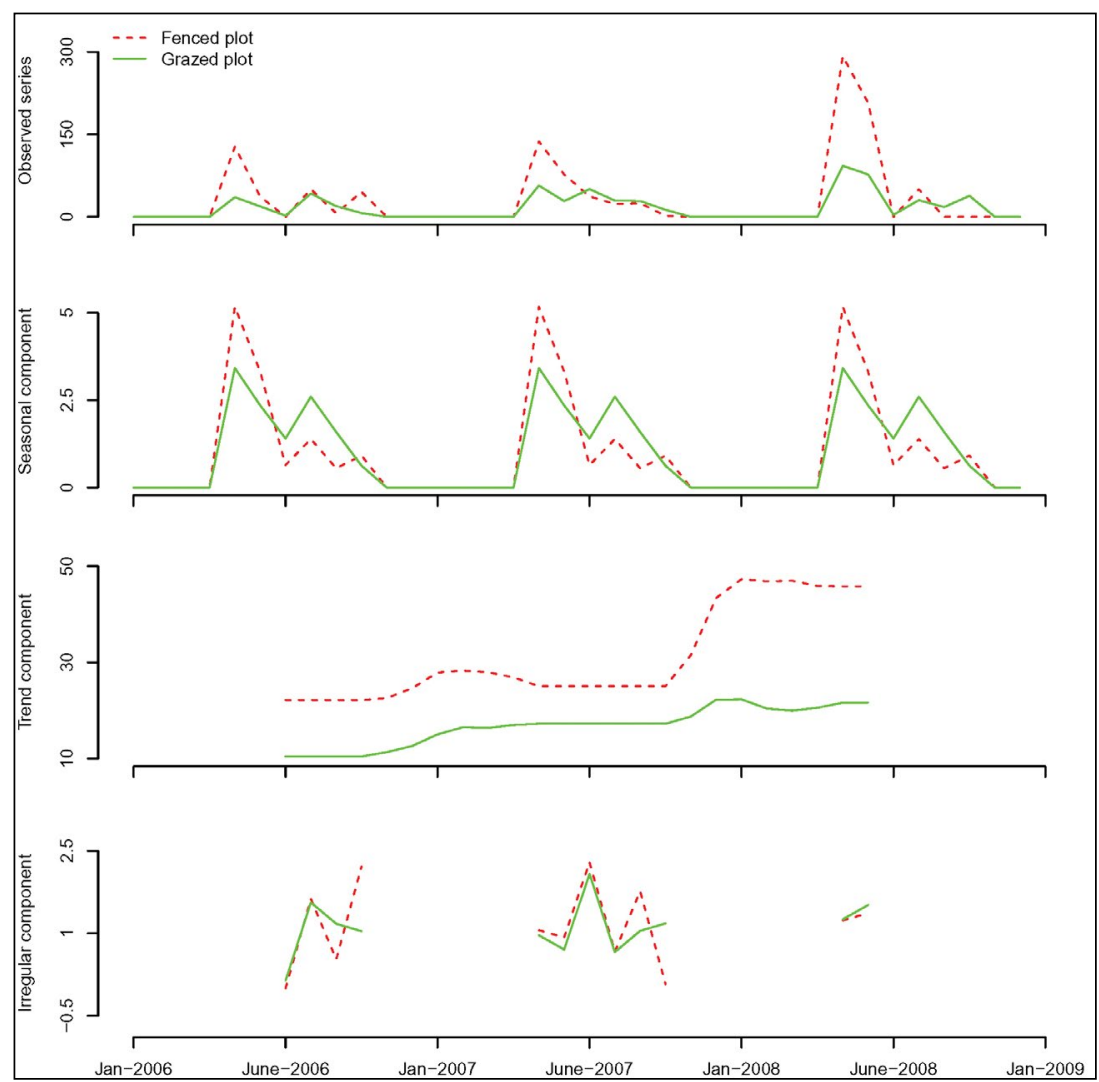

Figure 2. Multiplicative decomposition of monthly ANPP measured in Aralar field plots.

Productivity (dry matter in $\mathrm{g} \mathrm{m}^{-2}$ per month) is plotted in green (averaged ANPP under grazing conditions) and in dashed red (averaged ANPP measured in the fenced plots).

Decomposition shows larger seasonal components under exclusion conditions. Trend components show high monthly productivities in 2008, also more markedly in exclusion. All components are given in $\mathrm{g} \mathrm{m}^{-2}$ per month.

\subsection{Exponential smoothing forecasts}

As revealed by visual inspection and residual errors, both additive (Fig. 3a) and multiplicative (Fig. 3b) Holt-Winters models did not fit well the available data. Nonetheless, model fit was more acceptable for the grazed-level averaged series than for the fenced-level averaged series. For this reason, forecasting based in these models cannot be trusted, as revealed by the wide $95 \%$ prediction intervals. 


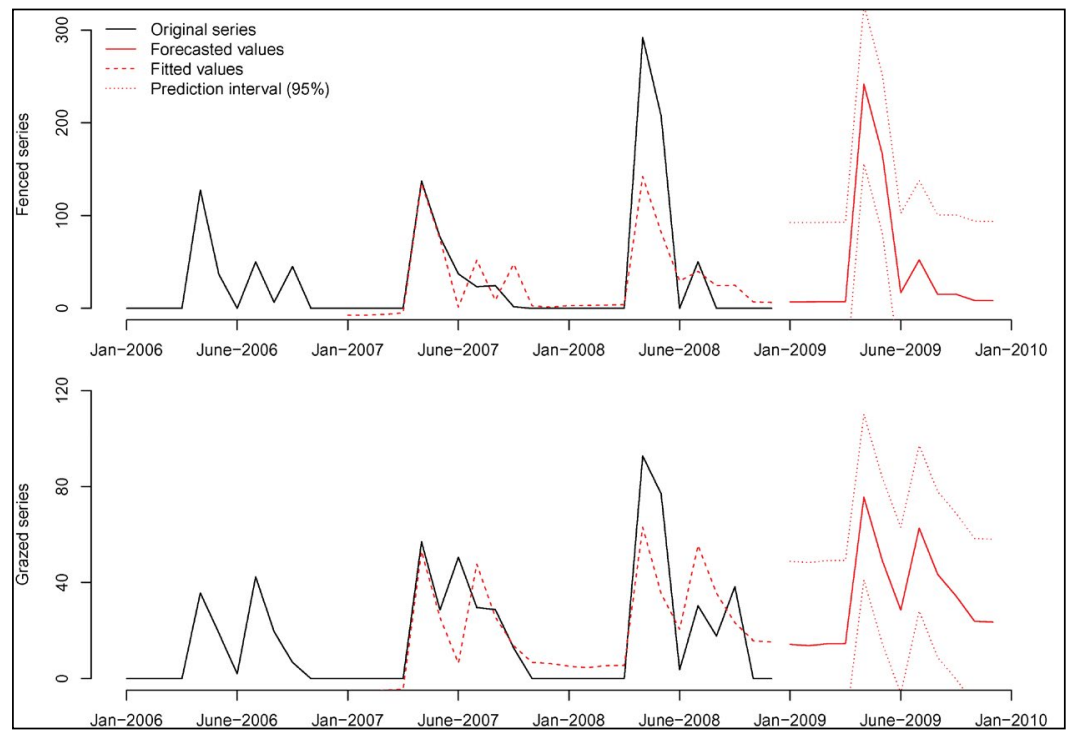

Figure 3a. Additive Holt Winters methodology forecasts. Forecasted productivity (dry matter in $\mathrm{g} \mathrm{m}^{-2}$ per month) is between mean values of 2006 and 2008. Only two peaks are predicted at the end of both series. The sum of square errors (SSE) is equal to 45194 for the fenced series, whereas equal to 7157 for the grazed series.

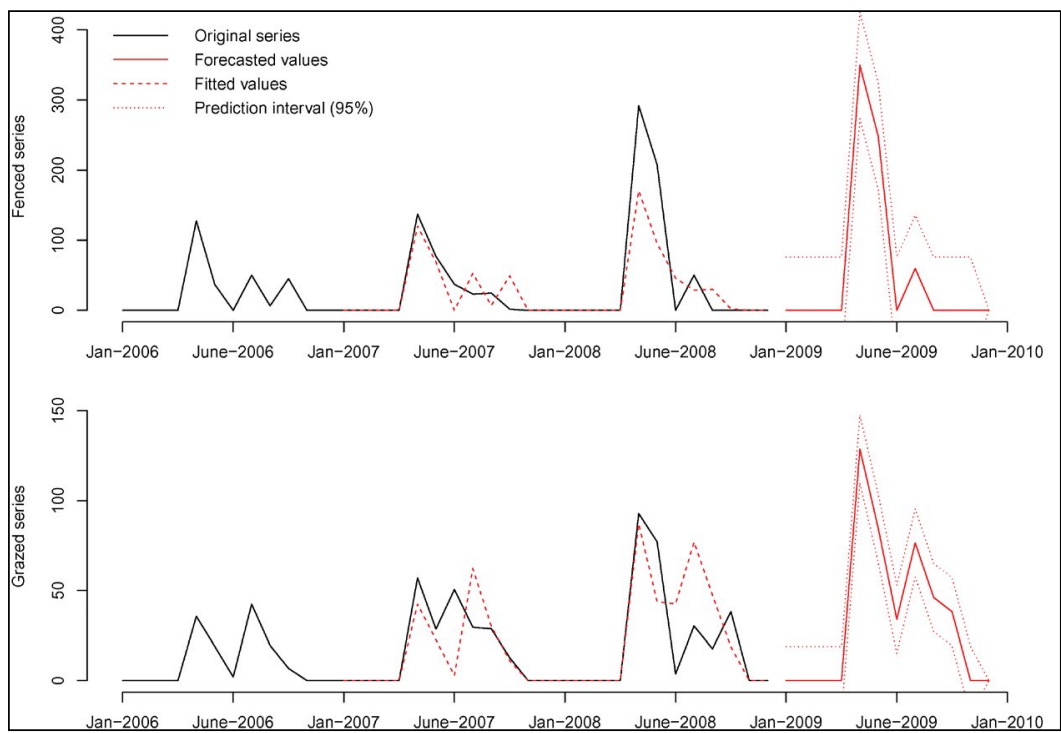

Figure 3b. Forecasts for 2009 after multiplicative Holt-Winters method. The increasing trend of productivity (dry matter in $\mathrm{g} \mathrm{m}^{-2}$ per month), a feature present in this short time series, leads to higher future values. Two seasonal peaks are forecasted in both treatments. The sum of square errors (SSE) was equal to 35900 for the fenced series and to 9667 for the grazed series, thereby suggesting a better fit for the later. 


\subsection{ARIMA models forecasts}

No autoregressive or moving average processes were found with the exception of a first order seasonal autoregressive process. An especial effort was carried out to model outliers, which were included in the fitted models to satisfy residual normality requirements (Table 1). Thus, ANPP forecasts were produced through the equations specified in Table 1. ARIMA models, particularly in the case of the grazed-level series, fitted better the available data than Holt-Winters models and thereby forecasted more credible ANPP values (Fig. 4). Nonetheless, the prediction interval for the fenced-level series was huge (Fig. 4; Fig. S3 in Appendix 2, Supplementary Material).

Table 1. Maximum likelihood estimates for structurally equal ARIMA $\{(0,0,0)(1,1,0)$ [12]\} models of ANPP: Fenced level (exclusion) model without (Table 1.1) and with outliers

(Table 1.2), Grazing level models without (Table 1.3) and with outliers (Table 1.4). The symbol $\phi$ is the parameter of the autoregressive process; AIC = Akaike Information Criteria; $I O=$ Innovative Outliers.

Table 1.1. Fenced ANPP model without outliers.

\begin{tabular}{|l|l|}
\hline \multicolumn{1}{|c|}{ Parameter } & \multicolumn{1}{c|}{$\phi \mathbf{1}$} \\
\hline Estimate & -0.51 \\
Standard error & 0.21 \\
$\mathrm{t}$-test value & -2.40 \\
$\mathrm{p}(>|\mathrm{t}|)$ & 0.011 \\
\hline$\sigma^{2}$ estimated as 7.33; log-likelihood= -59.78; AIC $=121.56$ \\
\hline
\end{tabular}

Table 1.2. Fenced ANPP fitted model including outliers.

\begin{tabular}{|l|l|l|l|l|l|}
\hline \multicolumn{1}{|c|}{ Parameter } & \multicolumn{1}{c|}{$\phi \mathbf{1}$} & \multicolumn{1}{c|}{ IO-29 } & \multicolumn{1}{c|}{ IO-30 } & \multicolumn{1}{c|}{ IO-33 } & \multicolumn{1}{c|}{ IO-34 } \\
\hline Estimate & -1.00 & 0.83 & 1.73 & -6.47 & -8.41 \\
Standard error & 0.00 & 0.01 & 0.01 & 0.01 & 0.01 \\
t-test value & & 98.64 & 205.57 & -770.64 & -1001.70 \\
$\mathrm{p}(>|\mathrm{t}|)$ & $<0.001$ & $<0.001$ & $<0.001$ & $<0.001$ & $<0.001$ \\
\hline \multicolumn{6}{|l}{$\sigma^{2}$ estimated as $1.84 \mathrm{e}^{-8} ; \log$-likelihood=171.37; AIC= -332.75 } \\
\hline
\end{tabular}

Table 1.3. Grazed ANPP model without outliers.

\begin{tabular}{|l|l|l|}
\hline \multicolumn{1}{|c|}{ Parameter } & \multicolumn{1}{|c|}{$\phi \mathbf{1}$} & \\
\hline Estimate & -0.70 & \\
Standard error & 0.15 & \\
t-test value & -4.67 & \\
$\mathrm{p}(>|\mathrm{t}|)$ & $<0.001$ & \\
\hline \multicolumn{2}{|c|}{$\sigma^{2}$ estimated as $0.4669 ; \log$-likelihood $=-28.38 ;$ AIC $=60.76$} \\
\hline
\end{tabular}


Table 1.4. Grazed ANPP fitted model including outliers.

\begin{tabular}{|c|c|c|c|c|c|c|c|}
\hline Parameter & $\phi 1$ & IO-19 & IO-29 & IO-30 & IO-32 & IO-33 & IO-34 \\
\hline Estimate & 1.00 & 2.91 & 0.02 & 0.58 & 0.39 & -0.87 & 0.47 \\
\hline Standard error & 0.00 & 0.01 & 0.01 & 0.01 & 0.01 & 0.01 & 0.01 \\
\hline t-test value & & 373.00 & 2.40 & 74.91 & 49.68 & -111.71 & 59.78 \\
\hline $\mathrm{p}(>|\mathrm{t}|)$ & $<0.001$ & $<0.001$ & 0.011 & $<0.001$ & $<0.001$ & $<0.001$ & $<0.001$ \\
\hline
\end{tabular}

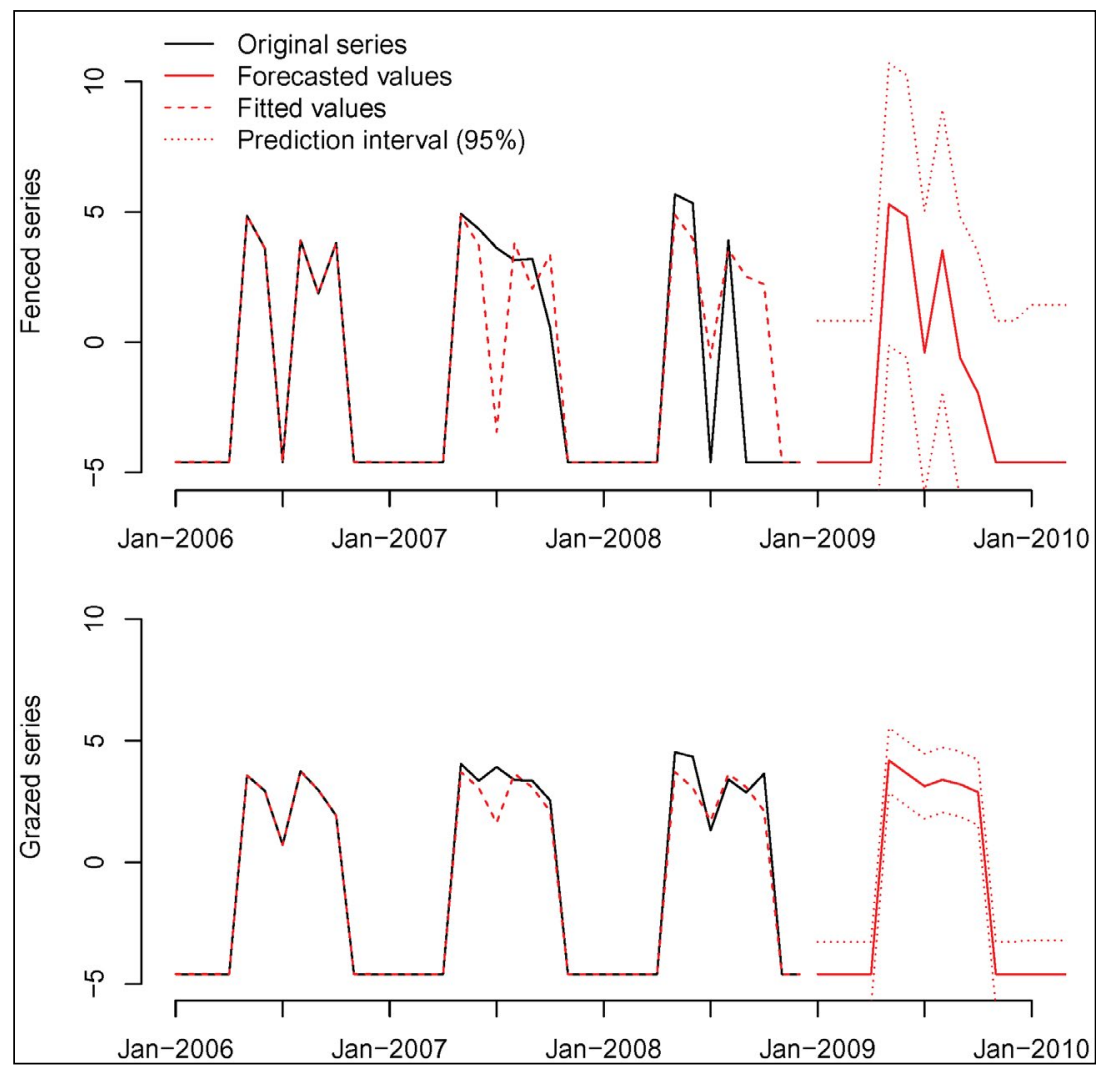

Figure 4. Productivity (dry matter in $g^{-2}$ per month) forecasts for 2009 after ARIMA methodology. Models which include outlier fitting cannot be used to produce forecasts due to methodological difficulties. Note that both the series and the forecasts have been transformed into a logarithmic scale. The prediction interval is large for the grazed series, but it is even larger for the fenced one. 


\section{Discussion}

Understanding both between- and within-year variations in ANPP is essential since ANPP is a key ecosystem property related with the energy sustaining the whole food web (McNaughton, 1985; McNaughton et al., 1989), as well as to biodiversity (De Angelis, 1980; Wright, 1983; Duffy et al., 2017). Any advances on the prediction of ANPP variations at annual or seasonal temporal scales would have implications for management. ANPP interacts with grazing pressure affecting multiple ecosystem functions (Díaz et al., 2007; Peco et al., 2017), thus any knowledge on future ANPP variations would allow a better adaptation of livestock carrying capacity based on productivity (Golluscio et al., 2015; Zhang et al., 2016), with consequent optimisation of related ecosystem functions. Because of the short series used, our study failed on accurately forecasting monthly ANPP variation. However, we found interesting features for management related to seasonal and annual variations on ANPP, and most importantly, future studies on forecasting ANPP will benefit from our detailed discussion on different statistical methodologies implemented, together with the $\mathrm{R}$ code, made freely available on the Appendix 1 of this work.

In this work, ANPP, which was measured straight away after fencing, was almost twice that measured under grazing conditions. Since, in broad terms, similar or even higher ANPP are often reported under grazing conditions because of greater renewal of leaf tissue and lower senescence rates, the greater ANPP found in our study in excluded vs. grazed plots requires additional explanation. We believe that this is a short-term effect, most likely due to the observed fact that the growth of the dominant grasses (Festuca nigrescens and Agrostis capillaris) was released when large grazers were prevented by fencing (Odriozola et al., 2017). Compared to forbs, grasses strongly determine ANPP, and grazing may cut down the response of grasses to increased temperature (Wang et al., 2012). Besides, Patton et al. (2007) described negative effects of grazing abandonment on ANPP, but only after long-term grazing exclusion, when litter build-up inhibited the growth of the plants, and this may also be the case for Aralar. Both explanations contribute to support our suggestion that the observed difference in ANPP in excluded vs. grazed plots is temporary.

\subsection{ANPP data collection}

Although productivity is defined as biomass produced in a given time interval (Singh et al., 1975), there are many ways to collect biomass data and many time intervals to produce time series. Grassland productivity has been traditionally measured by nondestructive methods such as plate meter and 3D quadrat with varying success (Redjadj et al., 2012), or more reliable estimates under annual calibrations as radiometer and point frame methods (Byrne et al., 2011). Grassland productivity has been measured by more accurate destructive methods as well. Within the latter, ANPP has been underestimated considering the final peak biomass as the total production (La Pierre et al., 2011; Craine et al., 2012; La Pierre et al., 2016), or overestimated by not differencing between live and dead biomass (Hu et al., 2007). Additionally, studies have usually investigated productivity analysing it as annual (La Pierre et al., 2011, 2016) and not allowing 
the study of within-year variation. In this study, we used a destructive methodology, measuring monthly ANPP and differencing death and live biomass. This methodology allowed us measuring ANPP accurately, as well as investigating its seasonal variations. Nevertheless, this was achieved by a very time-demanding procedure. The development of less laborious but sufficiently accurate techniques would facilitate the collection of equally detailed but longer time series than ours.

\subsection{Exponential smoothing forecasts}

The Holt-Winters models did not fit well, in general terms, with the data: for the within-year peaks, the high productivity corresponding to year 2008 and the null productivity of winter are data features that were not described appropriately by the fitted models. As a consequence, both the sum of square errors (SSE) and the prediction intervals were too large. For those reasons, the application of this method on these data series turned out to be not satisfactory. Regarding the results of the multiplicative Holt Winters method, the same conclusion applies, as both the SSE and prediction intervals were enormous.

Since Holt-Winters methods forecasted different trends according to whether they were multiplicative or additive, further discussion is required so as to shed light on these differences. First of all, it is important to highlight that the increasing trend is due to the extraordinary ANPP values corresponding to 2008, which have influenced positively all future predicted values. If these high values had been located in the middle of the series, the trend component would not have been as influencing as it is. However, in view of the positive relationship of ANPP with either precipitation (La Pierre et al., 2016) or temperature (Craine et al., 2012), the presence of a positive linear trend, as in the additive method, appears to be logical, because in the period 2006-2008 a positive trend in temperature is apparent in the meteorological data. Nevertheless, in the fenced series there are other influencing ecological drivers than climate, because the community is changing due to the lack of equalizing mechanisms that herbivores exert, and the field plots were not in a stable equilibrium. In this case, a bigger increment of ANPP was revealed, which was related with the sudden spread of highly productive dominant grasses (Odriozola et al., 2017), and this enhanced the positive trend. As observed in long-term grazer exclusion experiments (Patton et al., 2007), the initial extra productivity would most likely cease after a longer period of grazing abandonment, when litter accumulation inhibits plant growth. Anyway, despite being the slope modified, a positive linear trend as forecasted by the additive method could be adequate for several years. By contrast, there is no evidence (variance increasing with trend component) to support the exponential positive trend suggested in the multiplicative method.

Summarising, additive Holt-Winters forecasts appear to be more trustworthy than multiplicative ones under grazing conditions, although additional studies recording longer time series data would no doubt be required to clarify trends under exclusion conditions. The multiplicative model, though, captured seasonality better, because productivity was positive in winter in the additive forecasts. 


\subsection{ARIMA model forecasts}

ARIMA modelling did not lead to useful forecasting in either case, mainly for two reasons. On the one hand, the introduction of too many step functions to model outliers was inevitable in order to achieve a satisfactory model fit and reduce the residual errors. On the other hand, despite all these corrections, which inevitably introduced an unwanted mathematical complexity, the accuracy of the model was inadequate, a fact that is evidenced by the huge prediction intervals (especially under fenced conditions). These two reasons are, in turn, related with the shortness of the dataset. However, data variability in the grazed series was better captured using ARIMA modelling than using Holt Winters methods. In short, forecasts were not accurate and, once again, the collection of longer data series seems to be inevitable in order to obtain useful results from ARIMA modelling.

\subsection{Implications for management}

It is impossible to assess which of the methods is more appropriate for ANPP modelling, since both attempts have been unsuccessful. Nonetheless, although the main aim of this work (producing accurate forecasts) was not adequately satisfied, our analytical work and the script provided may be useful to apply in other longer-term datasets, or in combination with monitoring tools such as the one proposed by Primi et al. (2016). Additionally, our study did show other interesting features for grassland management. Seasonality in ANPP was proved, as in other studies which have linked it with the precipitation regime (Swemmer et al., 2007; Fabricante et al., 2009) or with plant phenology (La Pierre et al., 2011). This seasonality must, therefore, be considered at the time of planning the livestock management in the park. This will help to optimize the grassland utilization since it allows designing a temporal planning of the grazing so that livestock take advantage of the maximum peaks of forage.

As in many European grasslands (Pe'er et al., 2014) the reduction of livestock has been great in the mountains of the Cantabrian-Atlantic region, and the risk of woody plant encroachment due to the accumulation of biomass has been revealed (Gartzia et al., 2014; Lasanta-Martínez et al., 2005). Moreover, the decreasing trend in livestock is expected to accentuate in the future (Rounsevell et al., 2006). These grasslands with high conservation value (EC, 2013) are deeply linked to the action of herbivores. Experimental grazing exclusion has demonstrated that the decoupling of grassland ANPP and the livestock pressure has many unwanted consequences for their conservation, apart from shrub encroachment. These changes include loss of plant diversity (Odriozola et $a l ., 2017$ ); reduction on forage quality as reduced digestibility and nutrient content, and enhanced fibre content (Odriozola et al., 2014); and the related reduction on microbial activity and retarded nutrient cycling (Aldezabal et al., 2015).

In contrast to the current situation, other simulations of recovery of shepherding could be hypothesized. In this case, features also supported by other studies, like seasonality of the ANPP (Fabricante et al., 2009; La Pierre et al., 2011) and the increasing trend of the production (Craine et al., 2012; La Pierre et al., 2016), can help to increase 
the carrying capacity of the grasslands of the Aralar Natural Park. Active shepherding based on rotation systems might be used to create short-term abandoned fields, where forage production is enhanced. Moreover, the sheep flocks could also be actively guided to make better use of within-year (seasonal) productivity peaks.

\section{Conclusions}

The aboveground net primary production (ANPP) of an Atlantic mountain grassland system was modelled in order to attempt producing short-term forecasts. Monthly ANPP data were collected over three consecutive vegetative periods under grazing and exclusion conditions. Despite using several analytical methodologies, all of our attempts to forecast monthly ANPP accurately failed. This was mainly due to the relative shortness of the time series ( $n=36$ data points) and to the presence of numerous outliers, which has compelled us to introduce an undesired mathematical complexity in the ARIMA models. Nonetheless, our work revealed within-year variation in monthly ANPP and other useful information for the management of Cantabrian-Atlantic grasslands, such as the increase in productivity during the immediate years following grazing abandonment. Longer data collection should be necessary in order to use any time series forecasting methodology, although this would obviously imply more demanding inversion efforts.

\section{Acknowledgements}

This study received financial support from ETORTEK10/34 (Basque Government), UNESCO07/07 (University of the Basque Country) and AGL2013-48361-C2-1-R (Ministry of Economy and Competitiveness of the Spanish Government). We would like to thank all those who helped us with fieldwork and provided logistical support and technical assistance. In particular, we are grateful to Jose Antonio Irastortza (guard of the Aralar Natural Park), the botanists of ARANZADI Scientific Association, and the staff of Fraisoro Agricultural Laboratory.

\section{References}

Aalto, J., Roux, P.C., Luoto, M. 2013. Vegetation mediates soil temperature and moisture in Arctic-Alpine environments. Arctic, Antarctic, and Alpine Research 45 (4), 429-439. https:// doi.org/10.1657/1938-4246-45.4.429.

Adler, P.B., Seabloom, E.W., Borer, E.T., Hillebrand, H., Hautier, Y., Hector, A., Harpole, W.S., O'Halloran, L.R., Grace, J.B., Anderson, T.M. 2011. Productivity is a poor predictor of plant species richness. Science 333, 1750-1753. https://doi.org/10.1126/science.1204498.

Aldezabal, A., Moragues, L., Odriozola, I., Mijangos, I. 2015. Impact of grazing abandonment on plant and soil microbial communities in an Atlantic mountain grassland. Applied Soil Ecology 96, 251-260. https://doi.org/10.1016/j.apsoil.2015.08.013.

Altesor, A., Oesterheld, M., Leoni, E., Lezama, F., Rodríguez, C. 2005. Effect of grazing on community structure and productivity of a Uruguayan grassland. Plant Ecology 179 (1), 8391. https://doi.org/10.1007/s11258-004-5800-5.

BOPV, 2016. Decreto 84/2016, de 31 de mayo, por el que se designa Aralar (ES2120011) Zona Especial de Conservación. Boletín oficial del País Vasco (Spain) No. 174, 13/09/2016. 
Box, G. E. P., Jenkins, G. M., Reinsel, G. C. 2008. Time series analysis: forecasting and control. John Wiley \& Sons, New Yersey (USA), 746 pp.

Byrne, K.M., Lauenroth, W.K., Adler, P.B., Byrne, C.M. 2011. Estimating aboveground net primary production in grasslands: a comparison of nondestructive methods. Rangeland Ecology and Management 64, 498-505. https://doi.org/10.2111/rem-d-10-00145.1.

Chan, K., Ripley, B. 2012. TSA: Time Series Analysis. R package version 1.01.

Chapin III, F.S, Matson, P.A., Vitousek, P.M. 2011. Principles of terrestrial ecosystem ecology. Second Edition. Springer, New York (USA), pp.392.

Coghlan, A. 2014. A little book of R for Time Series. Wellcome Trust Sanger Institute, Cambridge (UK), $71 \mathrm{pp}$.

Craine, J.M., Nippert, J.B., Elmore, A.J., Skibbe, A.M., Hutchinson, S.L., Brunsell, N.A. 2012. Timing of climate variability and grassland productivity. Proceedings of the National Academy of Science 109 (9), 3401-3405. https://doi.org/10.1073/pnas.1118438109.

Cryer, J., Chan, K.S. 2008. Time series analysis with applications in R. Second Edition. Springer, New York (USA), $491 \mathrm{pp}$.

De Angelis, D.L. 1980. Energy flow, nutrient cycling and ecosystem resilience. Ecology 61 (4), 764-771. https://doi.org/10.2307/1936746.

Díaz, S., Lavorel, S., McIntyre, S., Falczuk, V., Casanoves, F., Milchunas, D.G., Skarpe, C., Rusch, G., Sternberg, M., Noy-Meir, I. 2007. Plant trait responses to grazing - A global synthesis. Global Change Biology 13 (2), 313-341. https://doi.org/10.1111/j.13652486.2006.01288.x.

Duffy, J.E., Godwin, C.M., Cardinale, B.J. 2017. Biodiversity effects in the wild are common and as strong as key drivers of productivity. Nature 549, 261-264. http://doi.org/10.1038/ nature23886.

EC 2013. Council Directive 2013/17/EU of 13 May 2013 adapting certain directives in the field of environment by reason of the accession of the Republic of Croatia. Official Journal of the European Union 158, 193-229.

Fabricante, I., Oesterheld, M., Paruelo, J.M. 2009. Annual and seasonal variation of NDVI explained by current and previous precipitation across Northern Patagonia. Journal of Arid Environment 73 (8), 745-753. https://doi.org/10.1016/j.jaridenv.2009.02.006.

Fay, P.A., Prober, S.M., Harpole, W.S., Knops, J.M.H., Bakker, J.D., Borer, E.T., Lind, E.M., MacDougall, A.S., Seabloom, E.W., Wragg, P.D. 2015. Grassland productivity limited by multiple nutrients. Nature Plants 1, 1-5. https://doi.org/10.1038/nplants.2015.80.

Fox, J.W. 2013. The intermediate disturbance hypothesis should be abandoned. Trends in Ecology and Evolution 28 (2), 86-92. https://doi.org/10.1016/j.tree.2012.08.014.

Frank, D.A., McNaughton, S.J. 1993. Evidence for the promotion of aboveground grassland production by native large herbivores in Yellowstone National Park. Oecologia 96 (2), 157 161. https://doi.org/10.1007/bf00317727.

Frank, D.A., Kuns, M.M., Guido, D.R. 2002. Consumer control of grassland plant production. Ecology 83 (3), 602-606. https://doi.org/10.2307/3071865

Gartzia, M., Alados, C.L., Pérez-Cabello, F. 2014. Assessment of the effects of biophysical and anthropogenic factors on woody plant encroachment in dense and sparse mountain grasslands based on remote sensing data. Progress in Physical Geography 38 (2), 201-217. https://doi. org/10.1177/0309133314524429.

Gass, T.M., Binkley, D. 2011. Soil nutrient losses in an altered ecosystem are associated with native ungulate grazing. Journal of Applied Ecology 48 (4), 952-960. https://doi.org/10.1111/ j.1365-2664.2011.01996.x.

Gibbons, W., Moreno, T. 2002. The geology of Spain. Geological Society of London, London (UK), 649 pp. 
Golluscio, R.A., Bottaro, H.S., Oesterheld, M. 2015. Controls of Carrying Capacity: Degradation, Primary Production, and Forage Quality Effects in a Patagonian Steppe. Rangeland Ecology and Management 68 (3), 266-275. https://doi.org/10.1016/j.rama.2015.03.002.

Holt, C.C. 2004. Forecasting seasonals and trends by exponentially weighted moving averages. International Journal of Forecasting 20 (1), 5-10. https://doi.org/10.1016/j. ijforecast.2003.09.015.

Hu, Z., Fan, J., Zhong, H., Yu, G. 2007. Spatiotemporal dynamics of aboveground primary productivity along a precipitation gradient in Chinese temperate grassland. Science in China Series D-Earth Sciences 50 (5), 754-764. https://doi.org/10.1007/s11430-007-0010-3.

Hyndman, R. 2017. forecast: Forecasting functions for time series and linear models. R package version 8 .

Hyndman, R., Khandakar, Y. 2008. Automatic time series forecasting: The forecast package for R. Journal of Statistical Software 27 (3), 1-22. https://doi.org/10.18637/jss.v027.i03.

Hyndman, R., Athanasopoulos, G. 2012. Forecasting: principles and practice. Otexts, 291 pp.

La Pierre, K.J., Yuan, S., Chang, C.C., Avolio, M.L., Hallett, L.M., Schreck, T., Smith, M.D. 2011. Explaining temporal variation in above-ground productivity in a mesic grassland: The role of climate and flowering. Journal of Ecology 99 (5), 1250-1262. https://doi.org/10.1111/j.13652745.2011.01844.x.

La Pierre, K.J., Blumenthal, D.M., Brown, C.S., Klein, J.A., Smith, M.D. 2016. Drivers of variation in aboveground net primary productivity and plant community composition differ across a broad precipitation gradient. Ecosystems 19 (3), 521-533. https://doi.org/10.1007/ s10021-015-9949-7.

Lasanta-Martínez, T., Vicente-Serrano, S.M., Cuadrat-Prats, J.M. 2005. Mountain mediterranean landscape evolution caused by the abandonment of traditional primary activities: A study of the Spanish Central Pyrenees. Applied Geography 25 (1), 47-65. https://doi.org/10.1016/j. apgeog.2004.11.001.

LeBauer, D.S., Treseder, K.K. 2008. Nitrogen limitation of net primary productivity in terrestrial ecosystems is globally distributed. Ecology 89 (2), 371-379. https://doi.org/10.1890/062057.1.

Loidi, J. 1983. Datos sobre la vegetación de Guipúzcoa (País Vasco). Lazaroa 4, 63-90.

McNaughton, S.J. 1985. Ecology of a grazing ecosystem: the Serengeti. Ecological Monographs 55 (3), 259-294. https://doi.org/10.2307/1942578.

McNaughton, S.J., Oesterheld, M., Frank, D.A., Williams, K.J. 1989. Ecosystem-level patterns of primary productivity and herbivory in terrestrial habitats. Nature 341, 143-144. https://doi. org/10.1038/341142a0.

McNaughton, S.J., Banyikwa, F.F., McNaughton, M.M. 1997. Promotion of the cycling of dietenhancing nutrients by african grazers. Science 278, 1798-1800. https://doi.org/10.1126/ science.278.5344.1798.

Mittelbach, G.G., Steiner, C.F., Scheiner, S.M., Gross, K.L., Reynolds, H.L., Waide, R.B., Willig, M.R., Dodson, S.I., Gough, L. 2001. What is the observed relationship between species richness and productivity? Ecology 82 (9), 2381-2396. https://doi.org/10.1890/00129658(2001)082[2381:WITORB]2.0.CO;2.

Odriozola, I., García-Baquero, G., Laskurain, N.A., Aldezabal, A. 2014. Livestock grazing modifies the effect of environmental factors on soil temperature and water content in a temperate grassland. Geoderma 235-236, 347-354. https://doi.org/10.1016/j. geoderma.2014.08.002.

Odriozola, I., García-Baquero, G., Fortin, M.J., Laskurain, N.A., Aldezabal, A. 2017. Grazing exclusion unleashes competitive plant responses in Iberian Atlantic mountain grasslands. Applied Vegetation Science 20 (1), 50-61. https://doi.org/10.1111/avsc.12277. 
Patton, B.D., Dong, X., Nyren, P.E., Nyren, A. 2007. Effects of grazing intensity, precipitation, and temperature on forage production. Rangeland Ecology and Management 60 (6), 656-665. https://doi.org/10.2111/07-008R2.1.

Pe'er, G., Dicks, L.V., Visconti, P., Arlettaz, R., Baldi, A., Benton, T.G., Collins, S., Dieterich, M., Gregory, R.D., Hartig, F. 2014. EU agricultural reform fails on biodiversity. Science 344 (6188), 1090-1092. https://doi.org/10.1126/science.1253425.

Peco, B., Navarro, E., Carmona, C.P., Medina, N.G., Marques, M.J. 2017. Effects of grazing abandonment on soil multifunctionality: The role of plant functional traits. Agriculture, Ecosystems and Environment 249, 215-225. https://doi.org/10.1016/j.agee.2017.08.013.

Primi, R., Filibeck, G., Amici, A., Bückle, C., Cancellieri, L., Di Filipo, A., Gentile, C., Guglielmino, A., Latini, R., Mancini, L.D. 2016. From Landsat to leafhoppers: A multidisciplinary approach for sustainable stocking assessment and ecological monitoring in mountain grasslands. Agriculture, Ecosystems and Environment 234, 118-133. https://doi. org/10.1016/j.agee.2016.04.028.

$\mathrm{R}$ core team 2015. A lenguage and environment for statistical computing: $R$ version 3.2.2. $\mathrm{R}$ Foundation for Statistical Computing, Vienna, Austria.

Redjadj, C., Duparc, A., Lavorel, S., Grigulis, K., Bonenfant, C., Maillard, D., Said, S., Loison, A. 2012. Estimating herbaceous plant biomass in mountain grasslands: A comparative study using three different methods. Alpine Botany 122 (1), 57-63. https://doi.org/10.1007/s00035012-0100-5.

Rounsevell, M.D.A., Reginster, I., Araújo, M.B., Carter, T.R., Dendoncker, N., Ewert, F., House, J.I., Kankaanpää, S., Leemans, R., Metzger, M.J. 2006. A coherent set of future land use change scenarios for Europe. Agriculture, Ecosystems and Environment 114 (1), 57-68. https://doi.org/10.1016/j.agee.2005.11.027.

Schrama, M., Veen, G.F.C., Bakker, E.S.L., Ruifrok, J.L., Bakker, J.P., Olff, H. 2013. An integrated perspective to explain nitrogen mineralization in grazed ecosystems. Perspectives in Plant Ecology, Evolution and Systematic 15 (1), 32-44. https://doi.org/10.1016/j. ppees.2012.12.001.

Semmartin, M., Aguiar, M.R., Distel, R.A., Moretto, A.S., Ghersa, C.M. 2004. Litter quality and nutrient cycling affected by grazing-induced species replacements along a precipitation gradient. Oikos 107, 148-160. https://doi.org/10.1111/j.0030-1299.2004.13153.x.

Singh, J.S., Lauenroth, W.K., Steinhorst, R.K. 1975. Review and assessment of various techniques for estimating net aerial primary production in grasslands from harvest data. Botanical Review 41 (2), 181-232. https://doi.org/10.1007/BF02860829.

Swemmer, A.M., Knapp, A.K., Snyman, H.A. 2007. Intra-seasonal precipitation patterns and above-ground productivity in three perennial grasslands. Journal of Ecology 95(4), 780-788. https://doi.org/10.1111/j.1365-2745.2007.01237.x.

Tang, Z., Deng, L., An, H., Yan, W., Shangguan, Z. 2017. The effect of nitrogen addition on community structure and productivity in grasslands: A meta-analysis. Ecological Engineering 99, 31-38. https://doi.org/10.1016/j.ecoleng.2016.11.039.

Wang, S., Duan, J., Xu, G., Wang, Y., Zhang, Z., Rui, Y., Luo, C., Xu, B., Zhu, X., Chang, X. 2012. Effects of warming and grazing on soil $\mathrm{N}$ availability, species composition, and ANPP in an alpine meadow. Ecology 93 (11), 2365-2376. https://doi.org/10.1890/11-1408.1.

Winters, P.R. 1960. Forecasting sales by exponentially weighted moving averages. Management Science 6 (3), 324-342. https://doi.org/10.1287/mnsc.6.3.324.

Wright, D.H. 1983. Species-energy theory : an extension of species-area theory. Oikos 41 (3), 496506. https://doi.org/10.2307/3544109.

Zhang, J., Huang, Y., Chen, H., Gong, J., Qi, Y., Yang, F., Li, E. 2016. Effects of grassland management on the community structure, aboveground biomass and stability of a temperate 
steppe in Inner Mongolia, China. Journal of Arid Land 8 (3), 422-433. https://doi.org/10.1007/ s40333-016-0002-2.

\section{Supplementary material}

See Supplementary Materials at

http://publicaciones.unirioja.es/revistas/cig2019/Salaberria_supplmat.pdf 